\title{
Short Goodbye, Long Horizon
}

Tinas $t$ is with regret that $I$ am announcing the end of my tenure as editor of Ecological Restoration. After founding the journal and providing almost 30 years of support, the University of Wisconsin-Arboretum has been compelled in part by financial challenges to close the editorial offices. As I write this, the University of Wisconsin Press has identified Steven N. Handel at the Center for Urban Restoration Ecology at Rutgers, the State University of New Jersey, as ER's next editor, which promises an exciting future for this journal. All current and prospective authors please note that Associate Editor Christina Reyes will provide critical editorial continuity in the short term.

After only three years as editor of Ecological Restoration I can say the job has taught me a tremendous amount, and perhaps only now am I feeling even partially qualified to competently editorialize on this broad, multifaceted, and rapidly expanding endeavor. I am indebted to the members of the journal's Advisory Board for their friendship and steady support, and for sharing their expertise. I have also enjoyed working with all of you who have submitted to the journal, and who represent a fascinating mix of scientific and philosophical orientations, united by a common desire to improve the world's environment. Editing Ecological Restoration has been an exciting experience, and looking ahead, I remain keenly interested in how the fields of restoration will develop.

I have found new work, and for the next three years will be involved in research on emerging collaborations between scientists and artists. Intertwined with arguments such as C.P. Snow's (1956) insistence on a fundamental disparity between the "two cultures" of the sciences and the humanities, there have been many other attempts to argue for and foster a creative unity of the arts and the sciences, E.O. Wilson's Consilience (1998) being a more recent example.

In preparing for this new research project and reading about new collaborations, I recognize the excitement generated by this kind of work: a bursting of disciplinary banks and a mixing of wildly different ideas as people not only communicate across intellectual divides, but feed new ways of thinking and new tools by opening up the innovation process to be more collaborative at a fundamental level.

Ecological restoration is a beautiful case study for art-science interdisciplinarity. I know ecological restoration will remain an enterprise to watch-driven as it is by both the urgency of environmental demise and the inspiration and desire afforded by human-nature connections.

In the first editorial for this journal, published in 1981 by the University of Wisconsin Arboretum, William R. Jordan III wrote that the journal founders viewed this publication as "a new forum ... [that] will help identify restoration and management as a new discipline in its own right-an art, and perhaps a science, borrowing from other disciplines, but distinct from them in having its own aims . . . and concerned with the development of ideas and techniques peculiarly its own." How right he was!

In this final issue for 2010, we are pleased to present a mix of articles representative of the diverse, distinctive ecological restoration effort. Along with articles on environmental policy-both U.S. and European-this issue of the journal offers pieces on urban ecological restoration in Milwaukee, Wisconsin, art-inspired restoration in Nebraska, and invasive species control in Spain. You can also read about tamarisk control in the Grand Canyon, dragonflies and vegetation structure in the U.S. prairie pothole region, and restoring natural capital in the Western Ghats of India. Enjoy, and best of luck to you in your restoration endeavors!

\section{Mrill Ingram}

Editor

\section{References}

Jordan, W.R., III. 1981. Restoration and Management Notes:

A Beginning. Restoration \& Management Notes 1:2.

Snow, C.P. 1956. The two cultures. New Statesman and Nation October 6:413-414.

Wilson, E.O. 1998. Consilience: The Unity of Knowledge. New York: Alfred A. Knopf. 